\title{
Development and Validation of a Rapid HPLC Method for Multiresidue Determination of Erythromycin, Clarithromycin, and Azithromycin in Aquaculture Fish Muscles
}

\author{
B. Habibi $^{1,3}$, I. Ghorbel-Abid ${ }^{1,2}$, R. Lahsini ${ }^{3}$, D. Chehimi Ben Hassen ${ }^{1}$ and M. Trabelsi-Ayadi ${ }^{1}$ \\ ${ }^{1}$ Laboratory of Materials Processing and Analysis (LMTA), National Institute for Research, \\ Physical and Chemical Analysis (INRAP), Biotech Pole Sidi-Thabet, 2032 Ariana, Tunisia \\ ${ }^{2}$ Faculty of Sciences of Bizerte, Laboratory of Chemistry, Applications to Natural Resources Substances and Environment, \\ LACReSNE, University of Carthage, 7021 Zarzouna, Bizerte, Tunisia \\ ${ }^{3}$ Laboratory of Research and Development, SIPHAT, BenArous 2036, Tunisia
}

Received: 14 September 2017; accepted: 19 October 2017

\begin{abstract}
An accurate, sensitive, and reproducible high-performance liquid chromatographic method with diode array detection has been developed for simultaneous determination of erythromycin, clarithromycin, and azithromycin residues in fish muscles. Analysis was carried out using a Shodex Asahipak high-performance liquid chromatography (HPLC) column, monitoring was at $210 \mathrm{~nm}$ and a mobile phase consisting of a mixture of acetonitrile and phosphate buffer $(\mathrm{pH} 11 \pm 0.05)$ in the ratio of 60:40 $(\mathrm{v} / \mathrm{v})$. Solid-phase extraction method was used in samples extraction and purification. Recoveries were in the range $72.0-92.2 \%$ with relative standard deviation (RSD) from $2.3 \%$ to $8.3 \%$. This method was validated for fish muscles in aquaculture following the commission decision 2002/657/EC criteria. It is demonstrated that the new method is robust for detection and quantification of the three macrolides residues. Decision limit $(\mathrm{CC} \alpha)$ was from 214 to $228 \mu \mathrm{g} / \mathrm{kg}$ and capacity of detection $(\mathrm{CC} \beta)$ was from 228 to $256 \mu \mathrm{g} / \mathrm{kg}$.
\end{abstract}

Keywords: Macrolides, residues, fish, HPLC-DAD, SPE, validation

\section{Introduction}

Antibiotics are used to prevent and treat diseases and microbial infections in humans and veterinary medicine especially in fish farms. They can be administrated as direct treatment or in feed additives because of their broad spectrum and their economic advantages [1]. However, emerging pollutants can appear and cause allergic reactions and other adverse effects, such as drug-resistant microorganisms [2].

Macrolide antibiotics constitute a very important class of antibacterial compounds highly active against Gram-positive and Gram-negative cocci. Moreover, they are also considered as the most efficient medicine against diseases produced by Mycoplasma species [3]. Macrolides are used for treatment of diseases that are common in food producing animals. They are critically important for animal health, and therefore, it is highly important that they must be used prudently to avoid resistance against major pathogens.

Different actions have been taken by international regulatory bodies, such as the European Union, the US Food and Drug Administration (FDA), China, and others, to set maximum residue levels (MRLs) for some macrolides in muscle tissue, fat, liver, and kidneys. MRL values were established for erythromycin, kitasamycin, spiramycin, tilmicosin, and tylosin. Roxithromycin, midecamycin, troleandomycin, josamycin, and others have no MRL values [4]. Erythromycin (Figure 1a), isolated from Streptomyces erythraeus in 1952, is considered as the most representative member of macrolides and the first used in medicine. Erythromycin is effective in vitro against Mycoplasma, gram-positive Cocci neisseria, some strains of haemophilus, corynebacterium, listeria, Pasteurella multocida, Brucella, and Treponema. Proteus pseudomonas and Escherichia coli are relatively resistant to the drug [5].

* Author for correspondence: habibi_belhassen@yahoo.fr
According to European regulation 2377/90, Codex, WHO/ FAO, US, Canada, Australia, etc. erythromycin residue in sea food muscle must be lower than $200 \mu \mathrm{g} / \mathrm{kg}$ [6]. Azithromycin (Figure 1b), derived from erythromycin, is used to treat certain bacterial infections, such as bronchitis, pneumonia, sexually transmitted diseases (STDs), and infections of the ears, lungs, sinuses, and skin [7]. Azithromycin is also used to treat or prevent disseminated Mycobacterium avium complex (MAC) infection. Clarithromycin [6-O-methyl erythromycin] synthesized by substituting a methoxy group for the C-6 hydroxyl group of erythromycin (Figure 1c) is a second-generation macrolide with broad spectrum of antibiotic activity [8]. It is active against the organisms which are responsible for bacterial exacerbations of lower respiratory tract infections.

Generally, the determination of antibiotics, including macrolide antibiotics, is mainly carried out by microbiological assays [9]. A number of analytical techniques such as capillary electrophoresis [10], various electrochemical detections, near infrared (NIR), and liquid chromatography-mass spectrometry are available for macrolide residues determination [11]. They have been applied for the determination and qualitative analysis of macrolide's compounds in raw materials, dosage forms, and biological samples. Almost all of these established analytical methods involve a complex separation step, laborious, and time-consuming. They require huge amount of solvents, lengthy experimental procedures for sample cleanup, and also demand expensive equipment that might not be available in many laboratories [12]. According to our knowledge, there is very few method in the literature that describes macrolide's separation with simple ultraviolet (UV) detection $[13,14]$. In this work, we have developed a simple and rapid high-performance liquid chromatography-diode array detection (HPLC-DAD) method for simultaneous determination of three macrolides in aquaculture fish muscles. Solid-phase extraction method has also been optimized. The robustness has been tested on real fish samples.

This is an open-access article distributed under the terms of the Creative Commons Attribution-NonCommercial 4.0 International License (https://creativecommons.org/licenses/by-nc/4.0/), which permits unrestricted use, distribution, and reproduction in any medium for non-commercial purposes, provided the original author and source are credited, a link to the CC License is provided, and changes - if any - are indicated. 


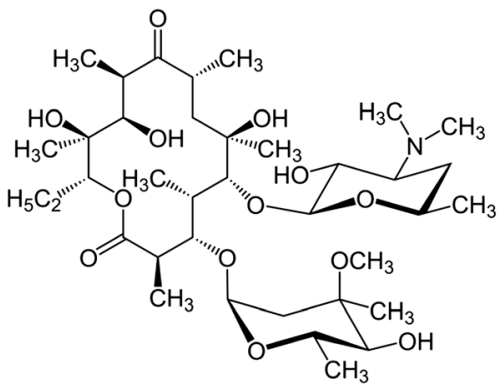

(a) Erythromycin

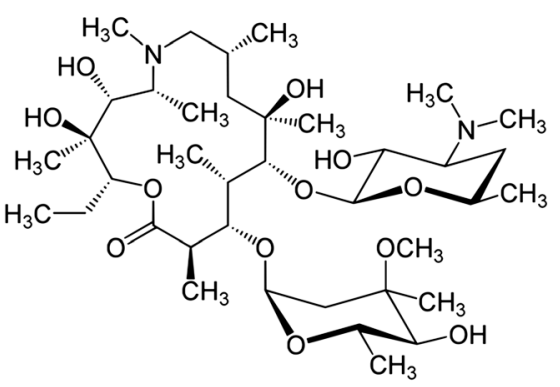

(b)Azithromycin

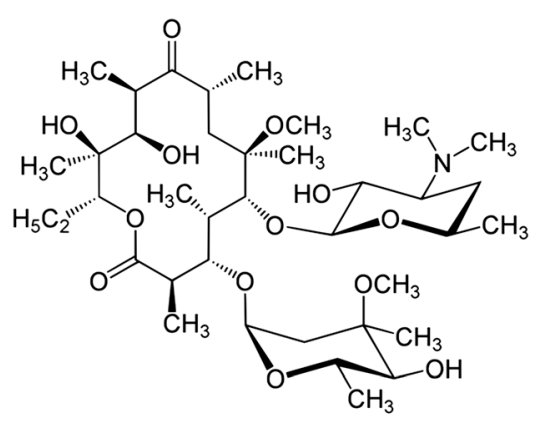

(c) Clarithromycin

Figure 1. The chemical structures of the studied macrolides

\section{Experimental}

Materials. Standards of erythromycin, clarithromycin, and azithromycin were kindly supplied by a local pharmaceutical company (SIPHAT, Tunisia). Methanol and acetonitrile (chromatographically pure for HPLC) were obtained from Prolabo (VWR International). Ammonia, monobasic potassium hydrogeno-phosphate, and potassium hydroxide were of analytical grade and obtained from Scharlau (Chemie, S.A, ES). Deionized water (Milli-Q; Millipore, Bedford, MA, USA) was used through the study. Solid-phase extraction (SPE) cartridges of Chromabond C18 (500 mg/6 mL), ODS C18 (Accubond, Agilent, $500 \mathrm{mg} / 6 \mathrm{~mL}$ ), Pack silica (SPE Supra-Clean ${ }^{\circledR}$ SI-S (Silica), $500 \mathrm{mg} / 3 \mathrm{~mL}$ Perkin Elmer), LC-18 Supelclean (LC-18 SPE encapped $500 \mathrm{mg} / 3 \mathrm{~mL}$, Supelco), and Sep-Pack C18 (Waters) were used for clean up the extracts.

Chromatographic Conditions. The HPLC system consists of a Perkin Elmer (Flexar) separations module equipped with an auto-sampler, quaternary pump, and a diode array detector. An Asahipak Shodex ODP-50 4E column $(250 \mathrm{~mm} \times 4.6 \mathrm{~mm}$ i.d., $5 \mu \mathrm{m}$ particles) was used for separating macrolides. The operating temperature of the column was set at $40{ }^{\circ} \mathrm{C}$. The mobile phase used was a mixture of acetonitrile and phosphate buffer adjusted at $\mathrm{pH} 11 \pm 0.05$ with potassium hydroxide in the ratio of 60:40 $(\mathrm{v} / \mathrm{v})$ in an isocratic mode at $1.0 \mathrm{~mL} / \mathrm{min}$. The injection volume was $20 \mu \mathrm{L}$. For the simultaneous determination of the three macrolides, the best detection with the UV detector was set at $210 \mathrm{~nm}$. Calibration curves were obtained by plotting concentrations against peak areas. Identification was performed by matching retention time and their spectral characteristic examined by diode array detection. The chromatographic data were collected and processed with a computer system for data acquisition (Total Chrom, Perkin Elmer).

Preparation of Solutions. Standard solution of each macrolide antibiotic compound was prepared by dissolving $20 \mathrm{mg}$ of each compound in $100 \mathrm{~mL}$ of a mixture of acetonitrile and water in the ratio of 75:25 $(v / v)$, sonicated for $5 \mathrm{~min}$, and then, diluted to $1 / 10$ with the same solvent. Solutions were immediately injected. Standard solutions were put in amber glass to prevent photodegradation [15].

Sample Preparation. Because of its higher production and consumption in Tunisia, the studied species of fish was Bream (Sparus auratus). Fish samples were collected from different aquaculture firms in Tunisia, immediately frozen below $-20^{\circ} \mathrm{C}$ with the aim of avoiding a possible antibiotic degradation during transport. Samples were analyzed within $24 \mathrm{~h}$ after they were acquired. Muscles were cut into small pieces and then ground. One gram of meat is previously weighed and introduced with $100 \mathrm{~mL}$ of a mixture of acetonitrile and water 75:25 $(\mathrm{v} / \mathrm{v})$ and then stirred for $15 \mathrm{~min}$ and centrifuged at $3500 \mathrm{rpm}$ for $15 \mathrm{~min}$. The supernatant is applied to SPE cartridge previously activated with $10 \mathrm{~mL}$ of methanol and $8 \mathrm{~mL}$ of water. Finally, macrolides were eluted with $10 \mathrm{~mL}$ mixture of methanol and ammonia 95:5 $(v / v)$. The ultimate extract was filtered through $0.22 \mu \mathrm{m}$ nylon Millipore chromatographic filter for HPLC analysis. For blank sample, the edible tissues were collected from the local market, cut into small pieces, and ground. They were stored below $-20{ }^{\circ} \mathrm{C}$ until the time of analysis.

Optimization and Validation. In the current study, the effect of variation of mobile phase composition was investigated in attempts to improve the resolution and reduce analysis time. The effect of mobile phase $\mathrm{pH}$ and temperature on the retention time of each analyte was investigated. Then, because food matrix can vary in terms of complexity/content in natural product which may interfere with responses of matrix peaks on chromatograms, different cartridges were tested to ensure a good SPE procedure.

The optimized method was then validated for the three studied macrolides with MRL $200 \mu \mathrm{g} / \mathrm{kg}$, according to European Union decision [16]. The specificity was proved by studying the interference between analytes and blank samples at the elution times [17]. The linearity of the method was studied with nine different calibration levels of mixed standard solution containing $1.2-2.8 \mu \mathrm{g} / \mathrm{mL}$ of each macrolide. The responses (peak area of analyte) were plotted versus the amount of analyte injected [18]. Each point is the mean of five independent measurements. The precision is the measure of variability of the results determined by calculating the relative standard deviation (RSD \%) where fish muscles were spiked at $50,100,200$, and $300 \mu \mathrm{g} / \mathrm{kg}$. The recoveries were determined with blank fish muscles that were spiked at levels of $0.25,0.5,1$, and 1.5 times the MRLs. Since MRLs for azithromycin and clarithromycin have not been specified, the spiked level used is the same as erythromycin $(200 \mu \mathrm{g} / \mathrm{kg})$. Two analytical parameters are recommended in EU decision: the critical concentration at risk $\alpha(\mathrm{CC} \alpha)$ also called decision limit, calculated by analyzing 20 blank samples fortified with macrolides at their MRLs (it is a way to take into account the variability of the method and the statistical risk of making a wrong decision) and the critical concentration at risk $\beta(\mathrm{CC} \beta)$ calculated as the decision limit plus 1.64 times the corresponding standard deviation $(\beta=5 \%)$ [19]. 


\section{Results and Discussions}

Method Development and Optimization. During the development of the method, several attempts were carried out in order to optimize the choice of mobile phase. Figure 2 shows the plot retention factor against proportion of organic solvent (acetonitrile) in the mobile phase of the proposed method [20]. A study was carried out with methanol such as organic modifier but did not give satisfactory results for resolution, peak shape, and analysis time. For $\mathrm{pH}$ optimization, obtained results showed that better resolution was observed when we increase $\mathrm{pH}$ values (see Table 1).

Therefore, according to column specifications, $\mathrm{pH} 11.0$ will be used in the developed method. Obtained resolutions were 4.18 between erythromycin and clarithromycin peaks and 3.86 between clarithromycin and azithromycin peaks. Experiments show that temperature has a significant effect on the resolution between studied compounds (see Table 2). The following study will be carried at a temperature of $40{ }^{\circ} \mathrm{C}$.

For sample extraction procedure, the ability to isolate macrolides from different fish samples was tested at the level of $200 \mu \mathrm{g} / \mathrm{kg}$ [21]. For simultaneous determination of the three studied compounds, best results were obtained with a Chromabond C18 cartridge (see Table 3).

A typical chromatogram of erythromycin, clarithromycin, and azithromycin was obtained under the conditions described below. Analytes were fully separated in 8 min with symmetrical peaks as seen in Figure 3. The system suitability parameters for studied compounds are reported in Table 4.

Method Validation. In order to verify the specificity of the newly developed method, 20 blank muscle samples of fishes were analyzed (see Figure 4A).

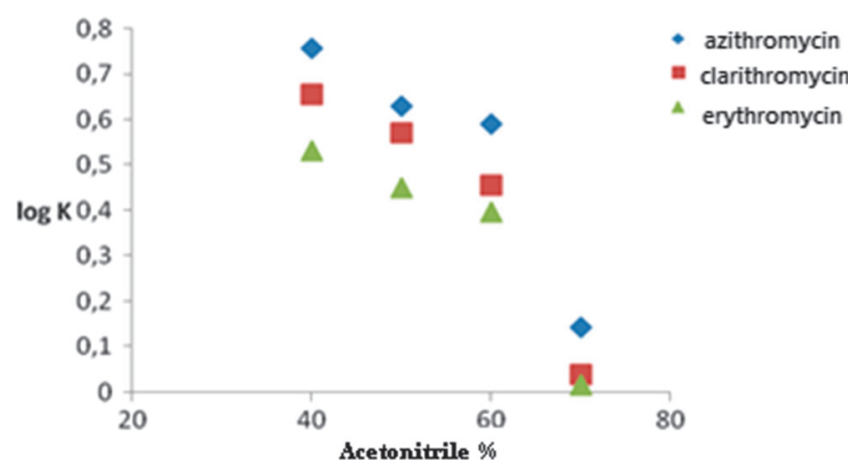

Figure 2. Capacity factor values for the studied compounds against proportions of acetonitrile

Table 1. Effect of the $\mathrm{pH}$ on the resolution, mean $(n=5)$

\begin{tabular}{lcccc}
\hline $\mathrm{pH}$ & 8 & 9 & 10 & 11 \\
\hline RS1 (erythromycin/clarithromycin) & 2 & 2.5 & 3.3 & 4.7 \\
RS2 (clarithromycin/azithromycin) & 3 & 3.3 & 4.1 & 5.2 \\
\hline
\end{tabular}

Table 2. Effect of the temperature on the resolution, mean $(n=5)$

\begin{tabular}{lcccc}
\hline Temperature & $25{ }^{\circ} \mathrm{C}$ & $30{ }^{\circ} \mathrm{C}$ & $35^{\circ} \mathrm{C}$ & $40{ }^{\circ} \mathrm{C}$ \\
\hline RS1 (erythromycin/clarithromycin) & 2.4 & 3 & 3.7 & 4.69 \\
RS2 (clarithromycin/azithromycin) & 2.0 & 2.7 & 3.6 & 5.21 \\
\hline
\end{tabular}

Table 3. Recoveries obtained for different cartridges, mean $(n=5)$

\begin{tabular}{lccc}
\hline Cartridge SPE & $\begin{array}{c}\text { Erythromycin } \\
(\%)\end{array}$ & $\begin{array}{c}\text { Clarithromycin } \\
(\%)\end{array}$ & $\begin{array}{c}\text { Azithromycin } \\
(\%)\end{array}$ \\
\hline Chromabond C18 & 70.03 & 89.76 & 88.84 \\
ODS C18 & 30.11 & 91.74 & 72.44 \\
Pack silica & 7.22 & 54.80 & 68.34 \\
LC-18 Supelclean & 89.71 & 44.33 & 60.75 \\
Pack C18 & 24.52 & 13.91 & 24.43 \\
\hline
\end{tabular}

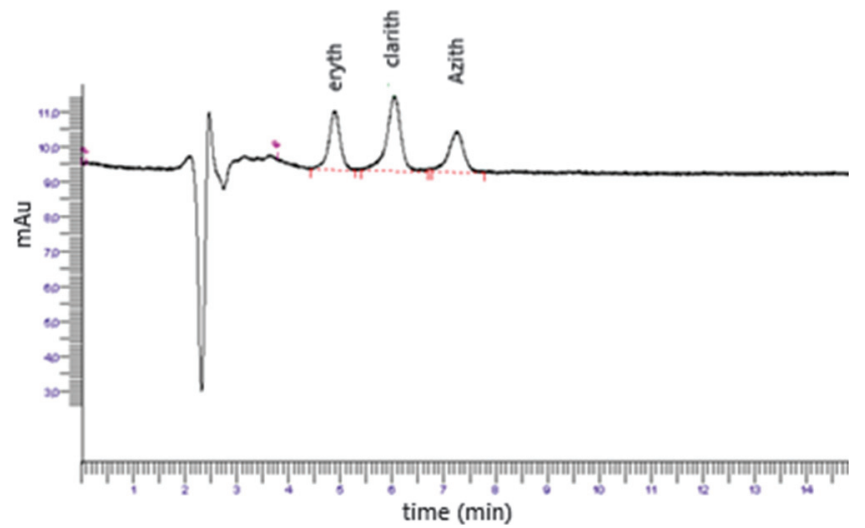

Figure 3. Standard solution of erythromycin, clarithromycin, and azithromycin chromatogram

Table 4. Results from system suitability study

\begin{tabular}{lccc}
\hline Compound & $T_{\mathrm{R}}{ }^{a}(\mathrm{~min})$ & $\mathrm{Rs}$ & $\mathrm{As}^{a}$ \\
\hline Erythromycin & 4.96 & - & 0.840 \\
Clarithromycin & 6.46 & 4.18 & 0.906 \\
Azithromycin & 7.34 & 3.86 & 0.912 \\
\multicolumn{2}{l}{$T_{\mathrm{R}}$, retention time; Rs, resolution; As, tailing factor. } \\
${ }^{a}$ Means from six replicate injections $(n=6)$. \\
\hline
\end{tabular}

Figure 4B shows the fish muscle chromatogram spiked at the MRL level. No interferences were observed at the elution times [22]. For the linearity study, all the obtained curves were found to be linear, and the coefficients of correlation ranged from 0.9974 to 0.9981 [23]. The obtained variability (relative standard deviation, RSD) of the slope and intercept varied between $0.65 \%$ and $1.32 \%$. The precision is the measure of variability of the results determined by calculating the \% RSD. The intra-day RSD values obtained for retention times averaged from $0.54 \%$ to $0.66 \%$ and for peak areas averaged from

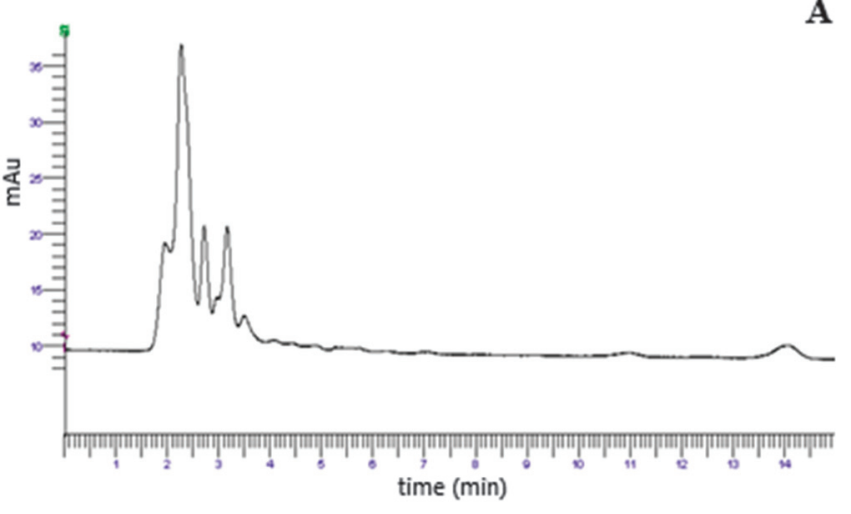

B

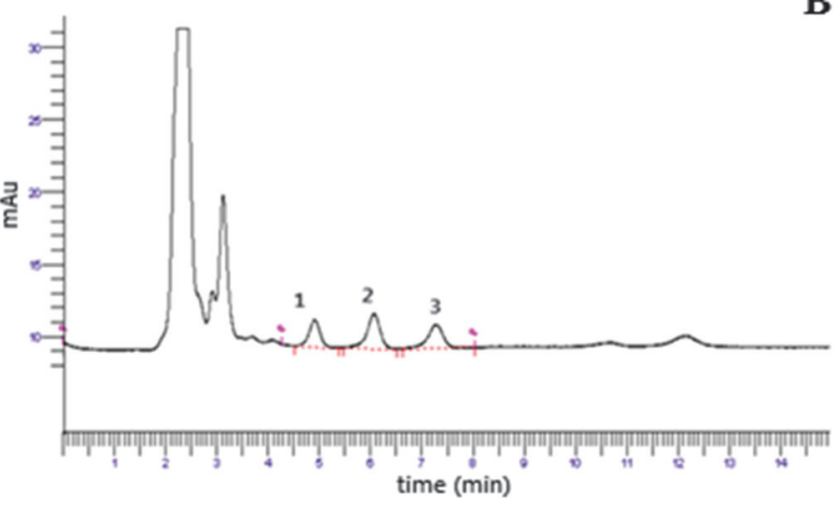

Figure 4. Typical HPLC chromatogram of a blank muscle sample (A); chromatogram of blank muscle sample spiked with $200 \mu \mathrm{g} / \mathrm{kg}$ of macrolides: 1, erythromycin; 2, clarithromycin; 3, azithromycin (B) 
$0.82 \%$ to $1.1 \%$. The inter-day RSD values obtained for retention times were varied from $0.94 \%$ to $1.2 \%$ and $1.52 \%$ to $2.6 \%$ for peak areas. The precision in fish muscles spiked at $50,100,200$, and $300 \mu \mathrm{g} / \mathrm{kg}$ exhibits good values and trueness for all compounds giving the coefficient of variation lower than $6.1 \%$ in repeatability and $8.3 \%$ in intra-day reproducibility [24]. With known amounts macrolides standards, recoveries ranged from $72.3 \%$ to $92.2 \%$. In all the previous tests, recoveries of the SPE method were taken into consideration. Results are depicted in Table 5. Decision limits $(\mathrm{CC} \alpha)$ were from 214 to $228 \mu \mathrm{g} / \mathrm{kg}$ and capacity of detection $(\mathrm{CC} \beta)$ were from 228 to $256 \mu \mathrm{g} / \mathrm{kg}$.

Method Application. The newly developed method described below has been applied for 30 samples bought from different local markets and corresponding to 6 different aquaculture sites, and the residue contents of studied compounds were calculated. Five samples from each market were analyzed. Obtained results are shown in Table 6. All peaks were identified by retention times, correspondent spectrum was obtained by $\mathrm{DAD}$ detection, and peak purity was also calculated in order to verify that there was no interfering peak in the resulting chromatograms. Obtained results indicated that some commercially available fishes contain erythromycin residues.

Table 5. Precision and accuracy of the suggested method

\begin{tabular}{lcccc}
\hline Compounds & $\begin{array}{c}\text { Spiked level } \\
(\mu \mathrm{g} / \mathrm{kg})\end{array}$ & $\begin{array}{c}\text { Mean } \\
\text { Recovery }^{a}\end{array}$ & $\begin{array}{c}\text { Within-day } \\
\text { RSD (\%) }\end{array}$ & $\begin{array}{c}\text { Between-day } \\
\text { RSD (\%) }\end{array}$ \\
\hline Erythromycin & 50 & 72.3 & 4.2 & 5.8 \\
& 100 & 86.1 & 3.2 & 2.3 \\
& 200 & 90.5 & 6.1 & 7.4 \\
Clarithromycin & 300 & 84.1 & 3.4 & 4.2 \\
& 50 & 92.2 & 5.3 & 7.0 \\
& 100 & 86.2 & 3.4 & 6.2 \\
Azithromycin & 200 & 90.2 & 3.8 & 8.0 \\
& 300 & 74.3 & 5.1 & 2.5 \\
& 50 & 92.1 & 4.8 & 8.3 \\
& 100 & 76.1 & 4.8 & 7.8 \\
& 200 & 80.2 & 3.5 & 5.0 \\
& 300 & 78.1 & 5.1 & 3.5
\end{tabular}

${ }^{a}$ Mean values represent six different samples for each concentration.

Table 6. Quantitative HPLC analysis of real fish sample at a dose of $\mu \mathrm{g} / \mathrm{kg}$

\begin{tabular}{lccc}
\hline $\begin{array}{l}\text { Product } \\
\text { code }\end{array}$ & Erythromycin & Clarithromycin & Azithromycin \\
\hline A & $124.4 \pm 6.6$ & nd & nd \\
B & nd & nd & nd \\
C & $14.1 \pm 3.1$ & nd & nd \\
D & nd & nd & nd \\
E & nd & nd & nd \\
F & nd & nd & nd \\
\multicolumn{2}{c}{ nd: not detected. } & & \\
${ }^{a}$ Mean $(n=5)$. & & \\
\hline
\end{tabular}

\section{Conclusion}

A convenient and simple HPLC-DAD method with rapid sample extraction has been developed for the determination of erythromycin, clarithromycin, and azithromycin in fish tissues. Recoveries of antibiotics spiked at levels of muscles $50-300 \mu \mathrm{g} / \mathrm{kg}$ averaged from $72.3 \%$ to $92.2 \%$ with relative standard deviation values less than $5 \%$. The use of an ODP-50 4E polymer-based column for reversed-phase chromatography, under alkaline condition, allowed the separation between the three macrolides. The obtained values confirm the precision and accuracy of the developed method. For real sample analysis, only residues of erythromycin were detected. Clarithromycin and azithromycin are not used in aquaculture field because of their high price. Obtained values for studied samples, collected from different aquaculture sites, met European Union regulation.

\section{References}

1. Guardabassi, L.; Jensen Lars, B.; Kruse, H. Guide to Antimicrobial Use in Animals April 2008, Wiley-Blackwell.

2. Cristofani, E.; Antonini, C.; Tovo, G.; Fioroni, L.; Piersanti, A.; Galarini, R. Analytica. Chimica. Acta 2009, 637, no. 1-2, pp. 40-46.

3. Gonźalez de la Huebra, M. J.; Vincent, U. J. Pharm. Biomed. Anal. 2005, 39, pp. 376-398.

4. Sismotto, M.; Jonas Paschoal, A. R.; Teles, Juliana A.; Estaiano, Renata A. R.; Felix Reyes, G. R. J. Food Comp. Anal. 2014, 34 (2), pp. 153-162.

5. Suárez, A.; Ellis, R. FAO/WHO Expert Committee 66th Meeting 29, 2006.

6. Sekkin, S.; Cavit, A. Antibacterial Drugs in Fish Farms: Application and Its Effects; Adnan Menderes University: Turkey, page 233.

7. Guidelines for Prevention and Management of Common Opportunistic Infections/Malignancies among HIV-Infected Adult and Adolescent Ministry of Health \& Family Welfare Government of India May 2007.

8. Shalf, H. J. Pharm. Res. 4, pp. 278-283.

9. Horie, M.; Takegami, H.; Toya, K.; Nakazawa, H. Analytical Chemica. Acta 2003, 492, 187-197.

10. Simon, B.; Hancu, G.; Braz, Á. G. J. Pharm. Sci. July/Sept. 2014, 50, São Paulo, 521-527.

11. Wang, J.; Leung, D.; Lenz, S. P. J. Agric. Food Chem. 2006, 54, pp. 2873-2880.

12. Lahane, S. B.; Deokate, U. A.; Ahire, S. K. Int. J. Pharm. Sci. Rev. Res. 2014, 26, No. 44, pp. 256-261.

13. Gaugain, M. J.; Anger, B. J. AOAC Int. 1999, 82, pp. 1046.

14. Shankar, B. P.; Manjunatha Prabhu, B. H.; Chandan, S.; Ranjith; Shivakumar, V. Veterinary World Vol. 2010, 3, pp. 241-246.

15. Yu, H.; Tao, Y.; Chen, D.; Wang, Y.; Yuan, Z. Food Chem. 2011, 124, pp. 1131-1138.

16. Commission Decision of 12 August 2002 implementing Council Directive 96/23/EC concerning the performance of analytical methods and the interpretation of results (2002/657/EC). Official Journal of the European Communication L221, 2002, 8 .

17. Lahsini, R.; Monser, L. Acta. Chromatogr. 2015, 27, pp. 449-460.

18. Lahsini, R.; Monser, L. Pharm. Chem. J. 2012, 46, pp. 127-131.

19. Carretero, V.; Balsco, C.; Pico, Y., J. Chromatogr. A 2008, 1209, pp. 162-173.

20 Taoa, Y.; Yua, G.; Chena, D.; Pana, Y.; Liua, Z.; Wei, H.; Penga, D.; Huang, L.; Wanga, Y.; Yuana, Z. J. Chromatogr. B 2012, 897, pp. 64-71.

21. Cinquina, A. L.; Longo, F.; Anastasi, G.; Giannetti, L.; Cozzani, R. J. Chromatogr. A 2003, 987, pp. 227-233, 2003.

22. Zhou, J.; Xue, X.; Li, Y.; Zhang, J.; Chen, F.; Wu, L. Food Chem. 2009, 115, pp. 1074-1080.

23. Shalaby, A. R.; Salama Nadia, A.; Abou-Raya, S. H.; Wafaa Emama, H.; Mehaya, F. M. Food Chem. 2011, 124, pp. 1660-1666.

24. Hellal, N.; Monser, L. J. Sep. Science 2008, 31, pp. 276-282. 